\title{
DIVERSITY AND ABUNDANCE OF PARASITIC WASPS (INSECTA: HYMENOPTERA) OF BANGLADESH
}

\author{
Mazumdar, S. and M. I. Miah \\ Department of Zoology, University of Chittagong, Chittagong 4331, Bangladesh
}

\begin{abstract}
A survey was conducted to study the diversity and population of parasitic Hymenoptera by using Malaise traps, from March 2014 to February 2015 in Chittagong University and Rajshahi University Campus. A total number of 173 genera was identified under 53 subfamilies, 23 families and 7 super families. Among the super families, the highest percentage of species individuals (59\%) in Chalcidoidea, and of genera (55\%) in Ichneumonoidea were recorded. The Species Richness (SR), $\mathrm{H}$ or $\mathrm{H}^{\prime}, \mathrm{H}_{\max }$, Evenness, Community dominance and Question of similarity indices were applied to determine the diversity and abundance of parasitic hymenoptera.
\end{abstract}

Key words: Parasitic Hymenoptera; Diversity; Abundance; Bangladesh.

\section{INTRODUCTION}

Diversity of organisms is essential for proper functioning of ecosystem (Sivaperuman and Venkataraman 2018). Indices describe general properties of communities that allow comparing different regions, taxa and trophic levels. Therefore, they are of fundamental importance for environmental monitoring and conservation (Mollenhauer et al. 2018). Insect is the earth's most diverse organisms, accounting 1,013,825 species out of total 1,635,250 species representing around $80 \%$ of world's recorded fauna and acting as central players in most of major biomes of the world notably the tropics where they display an enormous species richness and range of specializations (Roskov et al. 2015 and Loxdale 2016). Parasitic Hymenoptera constitutes about 20\% of all insect species and some $80-85 \%$ of hymenopterous species, and a total number of 68,918 species of parasitic hymenoptera has been described (Godfray 1994, Wisegeek 2015). Their importance is due to the fact that they are consumers in the food web and play a vital role, in a multitrophic interaction context, in natural communities (LaSalle and Gauld 1992). The present research program was undertaken to study the diversity and abundance of parasitic wasps in Chittagong University and Rajshahi University Campuses.

\section{MATERIAL AND METHODS}

Samplings were made weekly from March 2014 to February 2015 by using Malaise trap in Chittagong University Campus (CUC) (Lat. $22.46359^{\circ} \mathrm{N}$, Long. $91.7808^{\circ} \mathrm{E}$ ) and Rajshahi University Campus (RUC) (Lat. $24.3742^{\circ} \mathrm{N}$, Long. $88.6295^{\circ} \mathrm{E}$ ) based on their unique, different, and distinctly placed regions in Bangladesh. In briefly, CUC consists of about 1753.88 acres of land, of which about $72 \%$ land consists of hills and hillocks and remaining are either plains or valleys. The altitude of these hills and hillocks ranges from 10 to $90 \mathrm{~m}$ and rest are less than $30 \mathrm{~m}$ in height. Chittagong University Campus is situated on the south-eastern edge of Sitakunda hill range. Climate of Campus is typically tropical monsoon, characterized by hot humid summer and dry chilled winter. The region has a mean annual rainfall of about $275 \mathrm{~cm}$, temperature varies from $46^{\circ} \mathrm{F}$ in January to $95^{\circ} \mathrm{F}$ in May. Ecologically, CUC falls under the region of tropical evergreen forest. As a result of which it has changed to present form of unclassed state forest where herbs and shrubs are dominant (CU 2016, FUC 2014, Hossain 2017, Shuvo 2015 and WOCU 2018). Rajshahi University Campus is 753 acres $\left(3 \mathrm{~km}^{2}\right)$; climate is generally marked with monsoons, high temperature, considerable humidity and moderate rainfall; high temperature observed varies from 32 to $36{ }^{\circ} \mathrm{C}$ in the month of April to July, and minimum temperature recorded 
from 7 to $16{ }^{\circ} \mathrm{C}$ in January. Highest rainfall is observed during months of monsoon. Annual rainfall is about 1,448 mm (URG 2006, WOUR 2018 and RUA 2018). Many of the collected specimens were identified up to species level and the rest specimens were identified up to genus level using morphological and molecular technique. For morphological identification, mounted specimens were imaged with an Entovision Imaging System. Some doubtful specimens were sent for taxonomic identification and confirmation in the Department of Zoology, Malabar Christian College, Calicut 673001, Kerala, India. The specimens were preserved at Insect Museum of Department of Zoology at Chittagong University. Microsoft Office Excel 2007 was used for statistical analysis.

Biodiversity of the community from two different areas was calculated using the Shannon-Weiner diversity index $-H$ or $H^{\prime}=-\sum_{i=1}^{i=N} p i \log _{2} p i$, where, $p i$ is the proportion of each super families within the community, $\mathrm{N}$ expresses the total number of super families within the community. The evenness as well as community dominance was also evaluated from the Shannon-Weiner diversity index. However, the formulae for calculating evenness and community dominance are $-\frac{H^{\prime}}{H \max }$ and $\frac{Y 1+Y 2}{Y} \times 100$, respectively. In these equations, $H_{\max }$ expresses the maximum diversity of a community, $Y$ expresses the total number of genus within a community, $Y_{1}$ expresses the superfamily having the highest genus, and $Y_{2}$ expresses the superfamily having the second highest genus. The major vegetation associations of the localities are also recorded (Table 1).

Table 1. List of major plants available in two collection sites of Chittagong University Campus (CUC) and Rajshahi University Campus (RUC). ( $\mathbf{a}=$ Chittagong University Campus, $\square=$ Rajshahi University Campus).

\begin{tabular}{|c|c|c|}
\hline Family Name & Scientific and common name of plants & Plant status \\
\hline Amaranthaceae & Amaranthus spinosus L. (Prickly Amaranth) $\mathbf{\square}$ & Vegetable \\
\hline Apiaceaee & Coriand rum sativum L. (Coriander) $\square$ & Crop \\
\hline Asteraceae & Mikania micrantha Kunth (Heartleaf hempvine) $\square$ & Medicinal plant \\
\hline Brassicaceae & $\begin{array}{c}\text { Brassica campestris L. (Field mustard) } \square \square \\
\text { Brassica juncea } \text { (L.) Czern. (Indian mustard) } \mathbf{\square} \\
\text { Brassica napus } \text { var. dichotoma Prain (Rapeseed) }\end{array}$ & $\begin{array}{l}\text { Crop } \\
\text { Crop } \\
\text { Crop }\end{array}$ \\
\hline Caricaceae & Carica papaya L. (Papaya) $\square$ & Fruit \\
\hline Cucurbitacae & 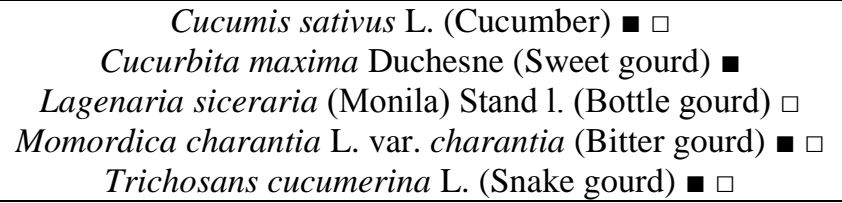 & $\begin{array}{l}\text { Vegetable } \\
\text { Vegetable } \\
\text { Vegetable } \\
\text { Vegetable } \\
\text { Vegetable }\end{array}$ \\
\hline Fabaceae & $\begin{array}{c}\text { Lablab purpureus } \text { (L.) Sweet subsp. purpureus (Bean) } \square \square \\
\text { Phaseolus vulgaris L. (French bean) } \square \\
\text { Vigna unguiculata (L.) Walp. (Yard-long bean) }\end{array}$ & $\begin{array}{l}\text { Vegetable } \\
\text { Vegetable } \\
\text { Vegetable }\end{array}$ \\
\hline Malvaceae & Abelmoschus esculentus (L.) Moench (Lady’s finger) घ $\square$ & Vegetable \\
\hline Musaceae & Musa paradisiaca L. (Banana) $\square$ & Fruit \\
\hline Myetaceae & Psidium guajava L. (Guava) $\square$ & Fruit \\
\hline Solanaceae & $\begin{array}{l}\text { Solanum lycopersicum L. (Tomato) } \square \square \\
\text { Solanum melongena L. (Brinjal) } \square \square\end{array}$ & $\begin{array}{l}\text { Vegetable } \\
\text { Vegetable }\end{array}$ \\
\hline Tiliaceae & Corchorus capsularis L. (Jute) $\square$ & Vegetable \\
\hline Verbenaceae & Clerodendrum viscosum Vent. $\square$ & Medicinal plant \\
\hline
\end{tabular}

\section{RESULTS AND DISCUSSION}

A total number of 173 genera was identified under 53 subfamilies, 23 families and 7 superfamilies. Among the identified genera, 145 species were confirmed under 93 genera. Of them, 83 genera of 22 families were DNA barcoded where 31 species under 19 genera were confirmed. All of the 173 species of parasitic hymenoptera are found in both of the study sites. The diversity of genus and species in 
Chalcidoidea are 62 and 86, respectively; in Ichneumonoidea 95 and 44, respectively; in Platygastroidea 8 and 6, respectively; in Diaprioidea 3 and 4, respectively; in Cynipoidea 3 and 3, respectively; in Ceraphronoidea 1 and 1 respectively; and in Evanoidea 1 and1, respectively (Table 2).

Table 2. Total number of identified genera and species in the present study.

\begin{tabular}{|c|c|c|c|c|c|c|}
\hline Superfamily & Genus & Genus of CUC & Genus of RUC & Species & Species of CUC & Species of RUC \\
\hline Ceraphronoidea & 1 & 1 & 0 & 1 & 1 & 0 \\
\hline Evanoidea & 1 & 1 & 1 & 1 & 1 & 1 \\
\hline Diaprioidea & 3 & 3 & 1 & 4 & 4 & 2 \\
\hline Platygastroidea & 8 & 8 & 3 & 6 & 6 & 2 \\
\hline Cynipoidea & 3 & 3 & 2 & 3 & 3 & 2 \\
\hline Chalcidoidea & 62 & 58 & 31 & 86 & 84 & 23 \\
\hline Ichneumonoidea & 95 & 91 & 22 & 44 & 42 & 17 \\
\hline Total & 173 & 165 & 60 & 145 & 141 & 47 \\
\hline
\end{tabular}

CUC $=$ Chittagong University Campus, RUC=Rajshahi University Campus

The most dominant Superfamily of species individuals (59\%) was observed in Chalcidoidea and of these genera $(55 \%)$ in Ichneumonoidea; followed by Ichneumonoidea (30\%) were in species whilist Chalcidoidea (36\%) in genera; the least was Ceraphronoidea and Evanoidea (1\%) in species even as no percentage in genera (Fig.1a).

Super families Platygastroidea (4\%), Diaprioidea (3\%), Cynipoidea (2\%), Ceraphronoidea (1\%) and Evanioidea (1\%) provided a little species diversity; meanwhile 5\%, 2\%, and $2 \%$ were observed for Platygastroidea, Cynipoidea and Diaprioidea in genera, respectively (Fig. 1b).
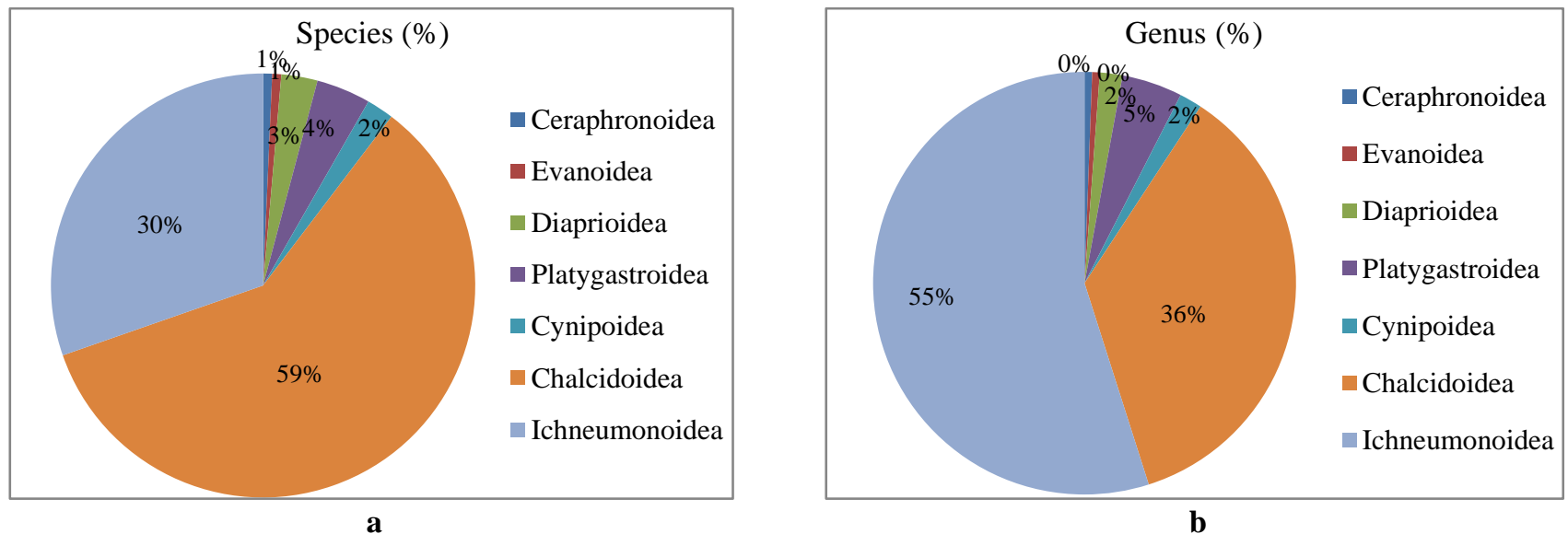

Fig. 1. Diversity of observed super families: a. species; and b. genus.

In CUC, a peak species diversity percentage (59\%) of Chalcidoidea was observed. Ceraphronoidea and Evanioidea were considerably lowest in number (only 1\%). For the time being, 2\%, 3\% and 4\% species were identified for Cynipoidea, Diaprioidea and Platygastroidea, respectively. Number of Ichneumonoidea (30\%) was nearly twice as identified species as Chalcidoidea (59\%) (Fig. 2a). In addition, the maximum genera in Ichneumonoidea (55\%) where Chalcidoidea (35\%) was in second position and Platygastroidea (5\%) in the third position; whereas $2 \%$ for Diaprioidea and Cynipoidea, and $1 \%$ for Evanioidea were observed and no population was found in Ceraphronoidea (Fig. 3a). 

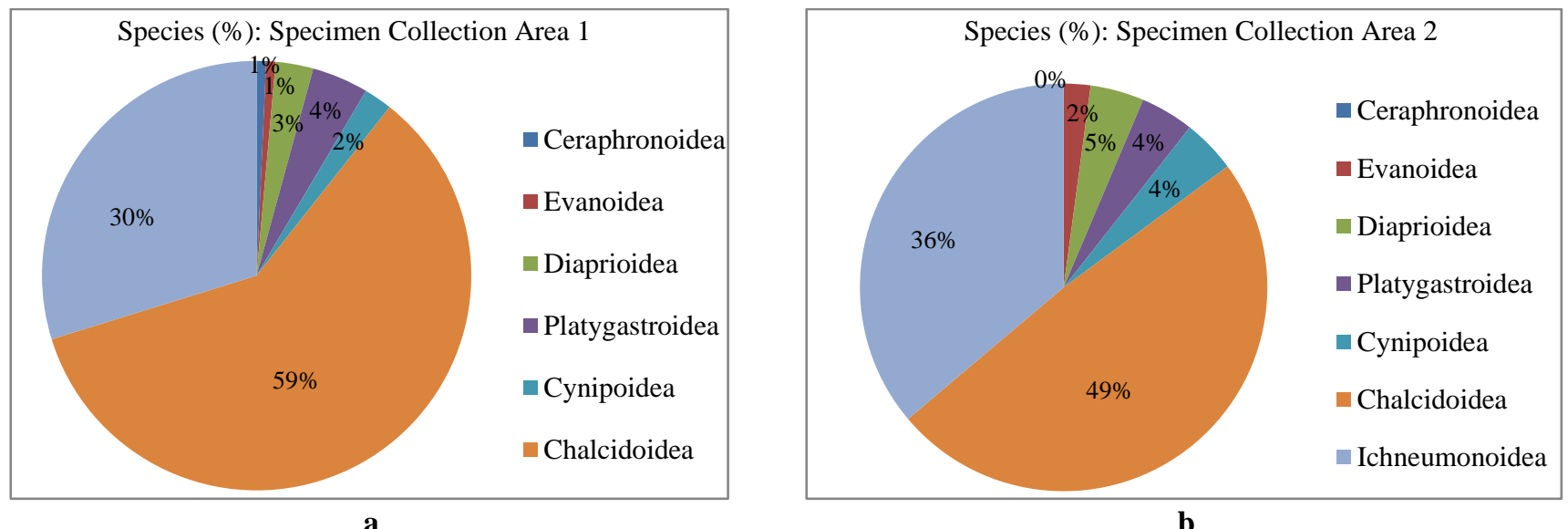

Fig. 2. Species diversity in percentage in different specimen collection area: a. area 1 (CUC); and b. area 2 (RUC).

In RUC, Chalcidoidea (49\%) and Ichneumonoidea (36\%) were dominant super families in percentage of species. Cynipoidea and Platygastroidea demonstrate similar percentage (4\%) and 2 in number separately. Though Diaprioidea ranged 5\% and 2\% for Evanioidea, no species was found in Ceraphronoidea (Fig. 2b). The majority of genera was occupied by Chalcidoidea (51\%) and Ichneumonoidea (37\%). The great diversified genera were identified in the rest superfamilies, such as 2\%, 2\%, 3\% and 5\% in Evanioidea, Diaprioide, Cynipoidea and Platygastroidea, respectively. No genus was recorded in Ceraphronoidea (Fig. 3b).

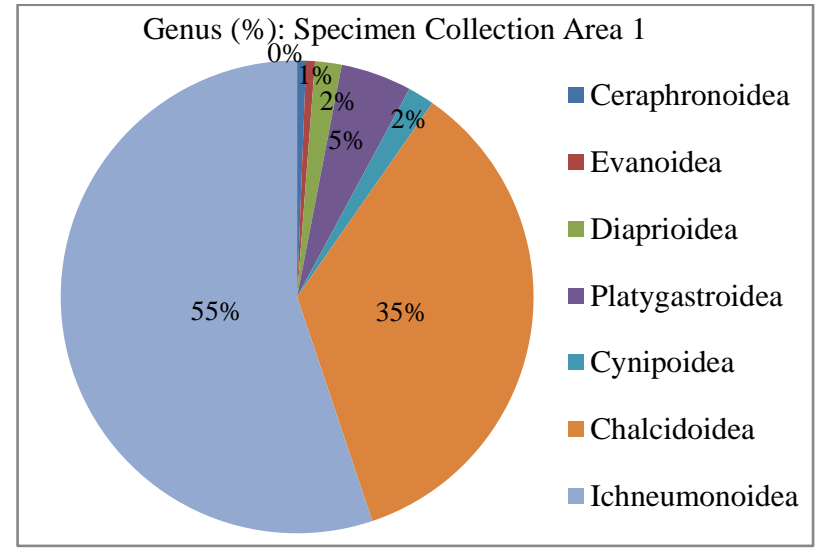

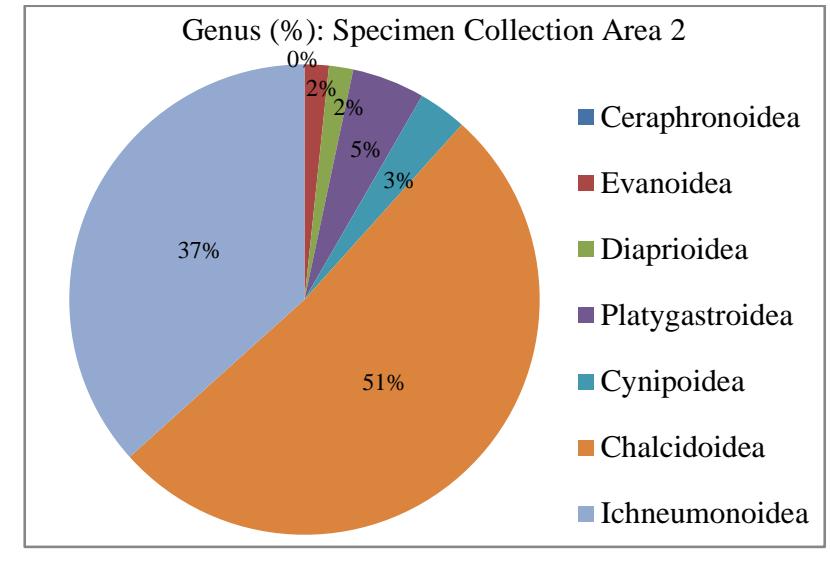

b

Fig. 3. Generic diversity in percentage in different specimen collection area: a. area 1 (CUC); and b. area 2 (RUC).

Species diversity is a parameter of community structure involving species and their abundance for the taxa (Wang et al. 2000). The present study revealed that over all diversity of parasitic hymenoptera in CUC is better than RUC. It was suspected that geographical and ecological conditions in sample collection areas may influence the diversity of parasitic hymenoptera. It is also reported that insect diversity could be affected by parameters related to vegetation structure, such as plant height, plant canopy, plant size or leaf shape (Haysom and Coulson 1998, Axmacher et al. 2004). Similarly, insect species richness often increases with an increase in vegetation height, with the highest diversity recorded in full-grown forests (Yi et al. 2011). Huber and Islam (2017) also stated that the greatest numbers of genera were found in natural habitat, presumably with many more plant species and potential insect hosts than experimental field plots planted with a single crop. 
Table 3. Biodiversity index assessment (Genus).

\begin{tabular}{|c|c|c|c|c|c|c|c|c|}
\hline \multirow[t]{2}{*}{ Super families } & \multicolumn{4}{|c|}{ Area 1 (CUC) } & \multicolumn{4}{|c|}{ Area 2 (RUC) } \\
\hline & Genus & pi & $\log _{2} p i$ & pilog 2 pi & Genus & $\overline{\text { pi }}$ & $\log _{2} p i$ & pilog 2 pi \\
\hline Ceraphronoidea & 1 & 0.01 & -0.15 & -0.002 & 0 & 0 & 0 & 0 \\
\hline Evanoidea & 1 & 0.01 & -0.15 & -0.002 & 1 & 0.02 & -0.18 & -0.004 \\
\hline Diaprioidea & 3 & 0.02 & -0.18 & -0.004 & 1 & 0.02 & -0.18 & -0.004 \\
\hline Platygastroidea & 8 & 0.05 & -0.231 & -0.01 & 3 & 0.05 & -0.231 & -0.01 \\
\hline Cynipoidea & 3 & 0.02 & -0.18 & -0.004 & 2 & 0.03 & -0.197 & -0.006 \\
\hline Chalcidoidea & 58 & 0.35 & -0.66 & -0.231 & 31 & 0.52 & -1.06 & -0.55 \\
\hline Ichneumonoidea & 91 & 0.55 & -1.16 & -0.64 & 22 & 0.37 & -0.697 & -0.258 \\
\hline Total & 165 & & 2.711 & -0.893 & 60 & & 2.545 & -0.832 \\
\hline Speices Richness (SR) & & & & 07 & & & & 07 \\
\hline $\mathrm{H}$ or $\mathrm{H}^{\prime}$ & & & & 0.893 & & & & 0.832 \\
\hline $\mathrm{H}_{\max }$ & & & & 2.81 & & & & 2.81 \\
\hline Evenness & & & & 0.32 & & & & 0.30 \\
\hline Community dominance & & & & $90.3 \%$ & & & & $88.3 \%$ \\
\hline Question of similarity & & & & 1 & & & & 1 \\
\hline
\end{tabular}

High diversity of parasitic Hymenoptera found in both CUC and RUC were 0.893 and 0.832 , respectively (Table 3). They were fairer in CUC (0.32) than in RUC (0.30). On the other hand, $\mathrm{H}_{\max }$ was equal in both CUC and RUC accounting 2.81 (Table 4).

Table 4. Biodiversity index assessment (Species).

\begin{tabular}{l|cccc|cccc}
\hline \multirow{2}{*}{ Super families } & \multicolumn{4}{c}{ Area 1 (CUC) } & \multicolumn{4}{c}{ Area 2 (RUC) } \\
\cline { 2 - 9 } & Species & $\mathrm{pi}$ & $\log _{2} \mathrm{pi}$ & $\mathrm{pilog} 2 \mathrm{pi}$ & Species & $\mathrm{pi}$ & $\log _{2} \mathrm{pi}$ & $\mathrm{pilog}_{2}$ pi \\
\hline Ceraphronoidea & 1 & 0.01 & -0.15 & -0.002 & 0 & 0 & 0 & 0 \\
Evanoidea & 1 & 0.01 & -0.15 & -0.002 & 1 & 0.02 & -0.18 & -0.004 \\
Diaprioidea & 4 & 0.03 & -0.20 & -0.006 & 2 & 0.04 & -0.22 & -0.009 \\
Platygastroidea & 6 & 0.04 & -0.22 & -0.009 & 2 & 0.04 & -0.22 & -0.009 \\
Cynipoidea & 3 & 0.02 & -0.18 & 0.004 & 2 & 0.04 & -0.22 & -0.009 \\
Chalcidoidea & 84 & 0.60 & 1.36 & -0.816 & 23 & 0.49 & -0.972 & -0.48 \\
Ichneumonoidea & 42 & 0.30 & -0.58 & -0.174 & 17 & 0.36 & -0.68 & -0.24 \\
\hline Total & 141 & & -2.84 & -0. & 47 & & -2.49 & \\
\hline Species Richness (SR) & & 07 & & & & 07 & & 0.751 \\
H or H & & & & 1.01 & & & & 2.81 \\
$\mathrm{H}_{\text {max }}$ & & & & 2.81 & & & & 0.27 \\
Evenness & & & & 0.36 & & & & \\
Community dominance & & & & $89.36 \%$ & & & \\
Quesion of similarity & & & & & & & & \\
\hline
\end{tabular}

Diversity as a community ecological concept refers to the heterogeneity in a community or assemblage of different organisms (Bakar and Khan 2016). Thus diversity is dependent upon the number of species present (Species richness, SR) and the distribution of all individuals among the species (Evenness) (Rahman et al. 2017). Therefore diversity index value of the present study may supports Lotfalizadeh et al. (2016) where the high species richness and Shannon indices, such as an area Interpretation of light trap catches of insects is affected by daily variation in weather that alters flight.

\section{ACKNOWLEDGMENTS}

The authors are indebted to former Professor Dr. Badrul Amin Bhuiya for his spontaneous support during the study period. Authors appreciated the service of Professor Dr. Md. Wahedul Islam, Institute of Biological Sciences, Rajshahi University, Bangladesh for his cordial support regarding the specimen collection from Rajshahi University Campus. Thanks are due to Professor Dr. Paul D.N. Hebert, Director, Biodiversity Institute of Ontario, University of Guelph, Guelph, Ontario, Canada for molecular 
identification of some specimens, and to Dr. Santhosh Shreevihar, Department of Zoology, Malabar Christian College, Calicut, Kerala-India for his cordial assistance in morphological identification.

\section{REFERENCES}

Axmacher, J. C., H. Tunte, M. Schrumpf, K. Muller-Hohenstein, H. V. Lyaruu and K. Fiedler. 2004. Diverging diversity patterns of vascular plants and geometrid moths during forest regeneration on Mt Kilimanjaro, Tanzania. J. Biogeography. 31(6): 895-904.

Bakar, M. A. and M. M. H. Khan. 2016. Diversity of insect pests and natural enemies as influenced by growth stages and pest management practices in rice. Bangladesh J. Agric. Res. 41(3): 461-470.

CU. 2016. "Chittagong University". hathazari.chittagong.gov.bd(in Bengali). Hathazari: hathazari.chittagong.gov.bd. Accessed on 07-09-2016.

FUC. 2014. "Faculty of the University of Chittagong". University of Chittagong. Accessed on 21-03-2015.

Godfray, H. C. J.1994. Patterns in the distribution of leaf-miners on British trees. Ecol. Entomol. 9: $163-168$.

Haysom, K. A. and J. C. Coulson. 1998. The Lepidoptera fauna associated with Calluna vulgaris: effects of plant architecture on abundance and diversity. Ecol. Entomol. 23(4): 377-385.

Hossain, S. 2017. "Chittagong University Museum". en.banglapedia.org. Banglapedia. Accessed on 30-11-2016.

Huber, J. T. and N. Islam. 2017. Introduction to the Mymaridae (Hymenoptera) of Bangladesh. ZooKeys. 675: 75.

Lasalle, J. and I. D. Gauld. 1992. Insect Parasitoids: Parasitic Hymenoptera \& biodiversity crisis. CAB International, London, UK., pp. 315-334.

Lotfalizadeh, H., Z. A. Bayegan and M. R. Zargaran. 2016. Species diversity of Chalcidoidea (Hymenoptera) in the rice fields of Iran. J. Entomol. Res. Soc. 18(1): 99.

Loxdale, H. D. 2016. Insect science - a vulnerable discipline? Entomol. Exp. Appl. 159(2):121-134.

Mollenhauer, H., M. Kasner, P. Haase, J. Peterseil, C. Wohner, M. Frenzel, M. Mirtl, R. Schima, J. Bumberger and S. Zacharias. 2018. Long-term environmental monitoring infrastructures in Europe: observations, measurements, scales, and socio-ecological representativeness. Sci. Total Environ. 624: 968-978.

Rahman, M., M. A. Maleque, M. S. Uddin and J. Ahmed. 2017. Abundance and diversity of beneficial insect and spider species on rice ecosystem in Sylhet region. J. Sylhet Agric. Univ. 4(1): 63-70.

Roskov, Y., L. Abucay, T. Orrell, D. Nicolson, T. Kunze, A. Culham, N. Bailly, P. Kirk, T. Bourgoin, R.E. DeWalt and W. Decock. 2015. Species 2000 and ITIS Catalogue of Life. Annual checklist. DVD. Species 2000: Naturalis, Leiden, the Netherlands.

RUA. 2018. www.ru.ac.bd/administration/paper. Accessed on 21-09-2015.

Shuvo, S. J. 2015. "চট্টগ্রাম বিশ্ববিদ্যালয় প্রাকৃতিক সৌন্দর্থের লীলাভূমি" (in Bengali). ournewsbd. Accessed on 21-3-2017.

Sivaperuman, C. and K. Venkataraman. 2018. Indian Hotspots: Vertebrate Faunal Diversity, Conservation and Management. Vol. 1. Springer, Singapore. 397 pp.

URG. 2006. University of Rajshahi: Glorious 52 years". University of Rajshahi. Accessed on 21-3-2015.

Wang, Z., C. Carpenter and S. S. Young. 2000. Bird distribution and conservation in the Ailao Mountains, Yunnan, China. Biol. Conserv. 92(1): 45-57.

Wisegeek. 2015. www.wisegeek.org/how-many-species-of-insect-are-re.htm. Accessed on 28-02-2015.

WOCU. 2018. https://en.wikipedia.org/wiki/University_of_Chittagong. Accessed on 16-07-2018.

WOUR. 2018. https://en.wikipedia.org/wiki/University_of_Rajshahi. Accessed on 21-3-2015.

Yi, Z., F. Jinchao, X. Dayuan, S. Weiguo and J. Axmacher. 2011. Insect diversity: addressing an important but strongly neglected research topic in China. J. Resour. Ecol. 2(4): 380-384. 